\title{
Psicologia na Universidade Metodista: um recorte da história
}

\section{Faculty of Psychology, Methodist University: a cut of history}

Marília Martins Vizzotto*

\begin{abstract}
Resumo
O texto faz um pequeno recorte da história do curso de psicologia na universidade Metodista de São Paulo, e procura ater-se ao período compreendido entre o final dos anos 1990 até 2001; período esse em que o Instituto Metodista passa a ser a Universidade Metodista de São Paulo e o curso de Psicologia sofre grandes transformações a partir das discussões das "Novas Diretrizes Curriculares" para os cursos de graduação no Brasil.
\end{abstract}

Palavras-chave: Psicologia; diretrizes curriculares; Universidade Metodista

\section{Abstract}

The text makes a short cut in the history of the psychology course at the Methodist University of São Paulo. The text covers a period from 1990 to 2001. It was during this period that the Methodist Institute became the Methodist University of São Paulo. At this time the Psychology course had great transformations, because there were changes in the Brazilian legislation.

Keywords: Psychology; curriculum; Methodist University

* Psicóloga, professora do Curso de Graduação e Pós Graduação stricto sensu em Psicologia na Universidade Metodista de São Paulo; Diretora de Faculdade e Coordenadora do curso de Psicologia entre 1997 - 2001. 
A história da Universidade Metodista de São Paulo (São Bernardo Campo) tem início com a criação da Faculdade de Teologia da Igreja Metodista em São Bernardo do Campo, em 1938. Somente em 1970 é que foi criado o IMS - Instituto Metodista de Ensino Superior. Em 1972 é criado o Curso de Psicologia. Com a consolidação do projeto pedagógico, conforme constado no Portal Metodista (s.d.), o IMS passou a figurar entre as mais conceituadas Instituições de Ensino Superior do país e isso permitiu que em 1997/1998 a instituição conquistasse o status de Universidade. Tiveram grande empenho nesse processo os professores Anísio Pereira e Jacob Daglian; de modo que, ao passar a ser universidade, ampliou-se o número de faculdades e cursos de graduação a serem oferecidos.

Nesta ocasião, no ano 1997, o então Diretor Geral do Instituto Metodista de Ensino Superior, Prof. Jacob Daglian (que mais tarde tornou-se primeiro Reitor da Universidade Metodista), convidou-me a ocupar o cargo de coordenadora do curso de psicologia, uma vez que o Prof. Péricles Oliveira Prado Filho (coordenador) havia de ocupar uma pasta na Pró-Reitoria Acadêmica. Após inúmeras reuniões, em meses de discussão, aceitei a difícil tarefa!

Para mim a função era nova. Era tão nova que eu sequer conhecia o curso em sua a estrutura e funcionamento; teria de coordenar um curso sólido, competente, com 42 docentes, incluindo-se os docentes do stricto sensu (que vinha já funcionando desde 1975 e do qual eu já fazia parte na época). Lembro que eu havia chegado nesta Universidade pelos idos de 1990 com a ajuda de um grande professor e supervisor que tive naquela época e do qual, mais tarde, tornei-me grande amiga - Dr. José Tolentino Rosa. Esse professor havia assumido o cargo de Diretor de Ensino e Pesquisa no então Instituto Metodista de Ensino Superior e, concomitantemente, lecionava no curso de mestrado em psicologia, sendo que pouco mais tarde assumiu também a coordenação da pós-graduação em psicologia. Aproveito-me também para expressar ao Dr. Tolentino, hoje aposentado de suas atividades docentes (Instituto Psicologia -USP e Metodista), a minha gratidão.

Enfim, "a olho nu" a tarefa seria fácil, pois com um curso de grande solidez e com funcionamento harmônico já havia 25 anos ..... 
Mas, sem nenhuma experiência, sem conhecimento nenhum acerca do próprio curso, seria abrolhoso!

Sorte minha! Na época encontrei professores e psicólogos dedicados, empenhados e competentes. Contava ainda com uma secretaria exemplar, que naquela época era composta pelas secretárias Marlene Lacerda, Andrea Fonseca Pasqualetti e Maria Cristina Trevisoni. Sorte maior foi ter tido a ajuda e principalmente o apoio do colegiado do curso (composto pelos professores) e das professoras chefes de Departamento Profa. Mariantonia Chippari e Profa. Marinês Santarosa Pereira Santucci (o curso era distribuído em dois departamentos: um de disciplinas básicas - gerenciado pela professora Mariantonia e um de disciplinas aplicadas - gerenciado pela professora Marinês; chefias departamentais que eram eleitas pelos docentes); além delas, contei com toda ajuda do Prof. Péricles - passando-me toda organização e a experiência, pois havia coordenado o curso por longos anos. Foram esses docentes que me ensinaram tudo que pude aprender sobre estrutura e funcionamento de graduação, além de conhecimento sobre políticas educacionais.

Foi então que encontrei um curso bem delineado, organizado e documentado; suas atas eram devidamente arquivadas, o 'Projeto Pedagógico' plenamente desenhado e tudo era impecavelmente organizado em seus arquivos. Seus laboratórios funcionavam muito bem, a clínica-escola era organizada; enfim, tudo isso transcorria bem. Houve desafios, mas tudo caminhava em harmonia; e foi o que me levou a pensar: "Ah! Vai ser fácil!" Até que, no ano seguinte, explodiram-se as discussões acerca das novas diretrizes curriculares para a Psicologia.

Estávamos na 'Era Fernando Henrique Cardoso' e o governo federal levava a cabo as políticas públicas para a educação nacional. A Reforma empreendida pelo governo, por meio do Ministério da Educação e Cultura - MEC empenhava-se em dar à educação uma nova ordem, tanto pedagógica quanto legal. Conforme escreveu o professor Jorge Fernando Hermida (HERMIDA, 2012) a proposta de reforma seguiu mudanças que já ocorriam no mundo todo e buscava adequar a educação superior a uma nova orientação, ou seja, dotada de uma concepção neoliberal. E essa mesma reforma, na época fora amplamente divulgada oficialmente, além de ter sido apoiada amplamente pela mídia. 
Certamente que as discussões já vinham acontecendo e a Educação já havia sido muito debatida na Assembleia Constituinte de 1987/1988; além disso, a educação foi o assunto que mais mobilizou diferentes setores da sociedade; principalmente os defensores do ensino público e gratuito. E, como ainda afirmou o professor Jorge Fernando Hermida:

[...] os anos que antecederam as discussões da Assembleia Constituinte foram fecundos em estudos sobre a educação nos textos constitucionais. Essas preocupações foram dando lugar à constituição e à articulação de movimentos sociais que foram fechando fileiras com a defesa dos princípios de uma ou outra forma de ensino que estavam colocados em debate, ou seja, em defesa do ensino público ou do ensino privado (HERMIDA, 2012, p.06).

É interessante lembrarmos o cenário em que estávamos na ocasião, e que, com a reeleição de Fernando H. Cardoso como Presidente do Brasil em 1998, houve uma consolidação neoliberal que figurou o Brasil entre os países capitalistas em desenvolvimento que buscavam estabilidade monetária e abertura do mercado para capitais internacionais. E, tal como ainda explica Hermida (2012) a análise da proposta no seu conjunto permitiu identificar uma série de mitos e contradições que serviram para elucidar os fundamentos filosóficos e políticos do projeto do Poder Executivo. Entre esses mitos estavam a igualdade de oportunidades e a erradicação da pobreza - e ambos alavancados pela educação como meio ideal para atingir esses objetivos.

Mas, voltemos à nossa história! Sim, pois, participei junto com vários colegas docentes, de incontáveis reuniões para discussão sobre as "Novas Diretrizes Curriculares" para cursos de Psicologia no Brasil. Foram longas discussões, buscavam-se o delineamento do perfil de formação do psicólogo, da implantação de ênfases curriculares; buscavam-se também a inserção de um núcleo básico e de estágios básicos, bem como o delineamento da formação específica em psicologia. Entre vários ensaios, foi impressa uma minuta que não expressava nem 'formação especializada' e nem 'formação generalista'. Mas, como bem diz Hoff (1999), a forma como fora 
descrita defendia uma formação generalista, e não uma graduação com caráter já especializado. Esta interpretação ficou fortalecida diante da proposição de um curso único e com denominação única - Curso de Psicologia.

Esta proposta levantou três aspectos positivos, como também anunciou Hoff (1999), no que diz respeito à concepção e formulação curricular. Primeiro o que se chamou de " princípios e compromissos da formação em Psicologia" que veio para nortear o currículo da psicologia, o que propiciou a articulação de conteúdos e não a simples agregação de disciplinas. Depois, o outro aspecto referiu-se à garantia de uma formação científica, permeada por um núcleo comum. Por último, a articulação teoria-prática, com atividades diversas que buscava aproximar gradativamente o estudante de situações representativas da atuação científico-profissional.

Assim, mesmo sofrendo algumas modificações e desdobramentos, houve um predomínio daquela proposta para os cursos de Psicologia no Brasil. Na ocasião, já em 1999, a então reitoria da Universidade Metodista, comandada pelo Dr. Davi Ferreira Barros e pela vice- reitora acadêmica Dra. Rinalva Cassiano, solicitaram que já fizéssemos modificações. Foi o que fizemos. Naquela altura tivemos de reorganizar todo o curso de Psicologia, inclusive a clínica- escola, transformando-a em um "Núcleo de Estudos, Pesquisa e Atendimento Psicológico". Mas, foi uma longa jornada! Convidamos a Dra. Carolina Martuscelli Bori ${ }^{1}$ para nos ajudar, inclusive a entender melhor aquilo que nos parecia tão confuso dentro da proposta das novas Diretrizes curriculares e palco de tantas discussões país afora. Entre tantas dúvidas estavam habilidades/competências, as ênfases, a formação em psicologia/generalista, os estágios básicos,

Dra. Carolina M. Bori - Cientista brasileira; uma das principais psicólogas brasileiras. Sua história confunde-se com a Psicologia no Brasil. Lutou pela consolidação da Ciência Psicológica na Universidade e com isso teve papel fundamental para a consolidação da ciência brasileira e foi reconhecida por isso, tanto que recebeu título de Presidente de Honra na Sociedade Brasileira para o Progresso da Ciência - SBPC, pois foi respeitada por todas as áreas do conhecimento científico no Brasil. Sobre Dra. Carolina M. Bori sugiro a leitura de: MATOS, M. A.; CARVALHO, A.M.A. Carolina Martuscelli Bori: uma cientista brasileira. Psicol. Reflex. Crit., Porto Alegre, v. 11, n. 2, p. 411-420, 1998. 
os estágios da formação, entre outras tantas dúvidas. Dra. Carolina trabalhou exaustivamente como Membro da 'Comissão de Especialistas em Psicologia do Ministério da Educação' e, conosco, teve imensa paciência e dedicação, pois foram idas e vindas de sua casa em São Paulo para São Bernardo do Campo (contando ainda que durante o trajeto, com o trânsito intenso, eu mesma travava longas discussões com ela). A professora ficou tão popular e querida entre os alunos que a turma que se formou naquele ano a convidou para ser 'Patrona'; ao que ela aceitou e, mesmo discreta, foi com muito entusiasmo que proferiu um longo e efusivo discurso em prol de uma formação científica sólida. Aproveito-me desta oportunidade, neste texto, para expressar minha eterna gratidão a essa cientista batalhadora, preocupada com a educação e com a disseminação do conhecimento científico brasileiro.

Logo em seguida o curso de "Psicologia" na Metodista também ganhou o status de Faculdade e agregou-se a ela o curso de Fonoaudiologia (muito bem desenhado e coordenado pela competente Dra. Carla Patrícia Hernandez Ribeiro César). Nessa época assumi então a direção dessa faculdade que contava com as duas graduações: Psicologia e Fonoaudiologia, além do stricto sensu - mestrado em Psicologia da Saúde, coordenado pela Dra. Eda Marconi Custódio.

Entre longas discussões colegiadas, fizemos reestruturações, respeitando o núcleo comum, também o que se chamavam estágios básicos (numa proposta de refinamento de 'observação psicológica') e definimos na ocasião 2 ênfases: "Psicologia das Organizações e do Trabalho" e "Psicologia Comunitária e da Saúde". Pensamos na nossa região, aquela historicamente voltada ao trabalho e que, dado ao seu avanço industrial desde o final dos anos 1950, teve impactos sociais e políticos positivos de padrão de acumulação, mas, por outro lado, sofreu consequências sociais e ambientais desfavoráveis - tanto no que tange à habitação, saneamento, pavimentação, transporte, abastecimento, energia, entre outros como, desordem ao meio ambiente, à oferta de serviços públicos, e problemas e saúde e educação. E foi esse quadro historio regional que nos fez optar por tais ênfases: a Psicologia que se debruçaria a estudar e aplicar esses conhecimentos científicos no que diz às organizações de trabalho e às relações homem-trabalho, bem como aquela Psicologia que se 
dedicaria a cuidar dos consequentes e graves problemas gerados nessa vasta região do $\mathrm{ABCD}$ paulista.

E assim os anos transcorreram, e no final de 2001 decidi deixar a direção da então Faculdade de Psicologia e Fonoaudiologia e me dedicar somente ao ensino e orientação, ou seja, a tudo aquilo que eu sempre senti prazer em realizar. Permaneci assim durante todos esses anos. O curso sofreu modificações, conforme também as "Diretrizes Curriculares" consolidada em 2011 o nortearam; o curso se manteve sólido, o corpo docente sempre caracteristicamente empenhado em suas atividades...... E tudo continuou!

E nesses vinte anos tenho acompanhado a formação em Psicologia na nossa IES (instituição de ensino superior) e também no país. Pude observar que houve um empenho do Estado em universalizar a educação nacional, e que caracterizou a proposta educacional neoliberal do governo de FHC, e houve também uma franca expansão do ensino superior a partir do final da década de 1990. Com essa expansão, houve, por um lado, um avanço no que diz respeito à autonomia institucional no que se referiu à organização de seus próprios projetos e planos de desenvolvimento institucionais; mas, por outro lado, aquilo que poderia ter sido também positivo tomou outros rumos, ou seja, por essa mesma proliferação de IES - instituições de ensino superior do setor privado e ampliação de vagas houve mudanças de perfil da população estudantil e, consequentemente, novas construções de alternativas metodológicas e organizacionais. Embora a expansão quantitativa seja um fator importante no próprio processo de democratização do ensino superior, as "brechas" (alternativas metodológicas ) dadas pelo Estado - naquilo que pode ser flexibilizado em termos de integralização do curso e cumprimento de horas - tem culminado na perda imensa de qualidade na formação superior. Isso, pois, o Estado tem sido ausente no acompanhamento da qualidade. E como escreveu Franco (2008) o papel do Estado é insubstituível em garantir o cumprimento de padrões mínimos aceitáveis de qualidade, articulando o oferecimento de cursos e compatibilizando-os às necessidades reais e demandas sociais.

De modo que, distante do próprio Plano Nacional de Educação - (Proposta da sociedade brasileira, 1997, p. 02) e conforme escreveu Hermida (2012) que tem como premissa a de que o ser humano é 
“[...] um ser ativo, crítico, construtor de sua própria cultura, da história e da sociedade em que vive, para tanto é imprescindível seu acesso a uma escola que, além de formação ampla, desenvolva valores e atributos inerentes à cidadania"; o cenário atual tem indicado uma escola oposta, pois tem sido notada dentro de uma perspectiva meramente mercadológica.

Ora, tudo isso parece então resultante de um processo de globalização da economia capitalista que tem, como explicou Frigotto (2006) colocado o Brasil numa posição bastante inferiorizada na divisão internacional do trabalho e que vem influenciar profundamente nas características internas não só na esfera econômica, mas também social e cultural.

Entendo, tal como também compartilhava nossa saudosa Dra. Carolina, que um padrão de qualidade educacional só pode ser obtido com políticas educacionais eficazes e contínuas. E aqui aproveito para lembrar uma posição crítica do Prof. Antonio Joaquim Severino (SEVERINO, 2008), no que concerne à educação superior e que diz que mesmo depois de aprovada a nova LDB (Lei de Diretrizes e Bases), fica nitidamente definida uma política de ensino superior que não responde apenas às exigências de regulamentação formal da própria LDB, consolidando uma posição leal e adepta das consignas da visão neoliberal da educação. Assim, continua o autor, o Decreto 2.306, de agosto de 1997, nova versão do Decreto 2.026, compõe uma reforma universitária sob essa inspiração.

Assim, entendo que o Estado, com sua legislação, tentou modernizar o ensino e acompanhar as mudanças sociais/mundiais de visão neoliberal. Assim sendo, embora seja correto dizer que um profissional formado no ensino superior terá de ter uma constante busca por aprendizado (aperfeiçoamento e aprimoramentos), a inconstância política brasileira tem impedido a consolidação de uma educação mais sólida e preparatória para uma vida de trabalho; de modo que esse profissional terá de buscar muito e muito mais! Hoje assistimos uma maior facilidade de ingresso e saída do estudante do ensino superior, mas, uma dificuldade maior de inserção deste no mundo do trabalho; não só pelas dificuldades atuais do mercado no que tange ao trabalho-emprego, mas também pelo grande despreparo - tanto técnico-científico como ético e humanista. E como bem o escreveu Severino (2008, p. 87) 
[...] sem prejuízo de seu compromisso de preparar as novas gerações para a esfera do trabalho, pelo adequado domínio dos saberes científico e tecnológico, a educação não pode deixar de investir também no amadurecimento de uma nova consciência social e no aprimoramento da formação cultural dessas gerações.

É possível dizer, que o ensino superior - tanto público quanto privado atravessa um período histórico e social com muitos desafios. E como ainda escreveu Prof. Antonio Joaquim Severino acerca dos desafios das universidades, esses se referem a um "conflito dilemático" que atravessa a própria realidade social brasileira da atualidade, ou seja, um embate entre uma educação embasada na teoria do capital humano e uma educação identificada com a teoria da emancipação humana; ou melhor, uma educação que se coloca a serviço do mercado e outra que deseja servir à construção de existência mais humanizada; onde, nas palavras do autor " [.... o trabalho é uma mediação essencial do existir histórico das pessoas e não um mero mecanismo da produção para o mercado (p. 87).

E assim nos mantemos na atualidade no ensino superior brasileiro. Não se pode negar que há ainda uma grande satisfação em observar crescimento de alunos empenhados e amorosos com a Psicologia - ciência e profissão. Há uma satisfação imensa em compartilhar fatos, conteúdos com os colegas, na manutenção de um bom convívio social e acadêmico, tanto nos momentos de discussão formal quanto informal - das reuniões colegiadas, congressos e encontros científicos aos encontros informais da sala do cafezinho; e até no grupo WatsApp - em nossos compartilhamentos de fotografias, anedotas e críticas ao sistema político .... Creio que isso nos faz melhores!

Mas, também não posso deixar de dizer que, não diferente do Brasil estamos nós em nossa micro região. Também observo um esforço imenso de professores que se dedicam a pensar e discutir com seus discentes sobre "ciência" e "existência", principalmente por nos encontrarmos numa formação em Psicologia. Todavia, há um evidente cansaço, e que me arrisco a conjecturar, não necessariamente em decorrência de sobrecarga de trabalho, mas muito mais relacionado à falta de autonomia, às restrições tidas no próprio processo 
educativo, e que por sua vez nada mais são do que consequências de um sistema político e educacional maior, que merece ser revisto.

Termino minha reflexão com uma fala de Franco (2008) ao expressar que ainda há uma distância entre a educação superior que temos e aquela de que necessitamos para que seja alcançado esse tão esperado padrão de qualidade. Ainda se faz distante a real democratização do acesso do sujeito ao ensino superior, bem como o fortalecimento da função social desse ensino.

\section{Referências}

FRANCO, A. P. Ensino Superior no Brasil: cenário, avanços e contradições. Jornal de Políticas Educacionais, n. 4, p. 53-63, Jul-Dez, 2008.

FRIGOTTO, G. Fundamentos científicos e técnicos da relação trabalho e educação no Brasil de hoje. In: LIMA, Júlio C.; NEVES, Lúcia M. W. (Orgs.) Fundamentos da educação escolar no Brasil contemporâneo. Rio de Janeiro: EPSJV/ Fiocruz, 2006. (p. 241-260).

HERMIDA, J.F. A reforma educacional na era FHC (1995/1998 e 1999/2002): duas propostas, duas concepções. In: Anais do IX Seminário Nacional de Estudos e Pesquisas "História, Sociedade e Educação no Brasil", Universidade Federal da Paraíba, João Pessoa, 31/07 a 03/08/2012, Anais Eletrônicos - ISBN 978-85-7745551-5. Disponível em: http://www.histedbr.fe.unicamp.br/acer_histedbr/seminario/ seminario9/PDFs/2.48.pdf . Acesso em 06/05/2016

HOFF, M. S. A proposta de diretrizes curriculares para os cursos de psicologia: uma perspectiva de avanços? Psicol. cienc. prof., Brasília , v. 19, n. 3, p. 12-31, 1999 . Disponível em: http://www.scielo.br/scielo.php?script=sci_arttext\&pid=S1414-98931999000300003\&lng=en\&nrm=iso. Acessado em 12/5/ 2015

PORTAL METODISTA. História, S.d. Disponível em: http://portal.metodista.br/ balanco-social/sobre/historia. Acessado em 02/06/2015

SEVERINO, A. J. O ensino superior brasileiro: novas configurações e velhos desafios. Educar, UFPR Curitiba, n. 31, p. 73-89, 2008.

Contato da autora:

Email : marília.vizzotto@metodista.br

mariliamartinsvizzotto@gmail.com

Recebido em 09/09/2015

Aceito em 10/02/2016 